\title{
Upwelling and associated heat flux in the equatorial Atlantic inferred from helium isotope disequilibrium
}

\author{
Monika Rhein, ${ }^{1}$ Marcus Dengler, ${ }^{2}$ Jürgen Sültenfuß, ${ }^{1,3}$ Rebecca Hummels, ${ }^{2}$ \\ Sabine Hüttl-Kabus, ${ }^{1,3}$ and Bernard Bourles ${ }^{4,5}$ \\ Received 31 August 2009; revised 10 March 2010; accepted 5 April 2010; published 20 August 2010.
}

[1] Upwelling velocities $w$ in the equatorial band are too small to be directly observed. Here, we apply a recently proposed indirect method, using the observed helium isotope $\left({ }^{3} \mathrm{He}\right.$ or $\left.{ }^{4} \mathrm{He}\right)$ disequilibria in the mixed layer. The helium data were sampled from three cruises in the eastern tropical Atlantic in September 2005 and June/July 2006. A onedimensional two-box model was applied, where the helium air-sea gas exchange is balanced by upwelling from ${ }^{3} \mathrm{He}$-rich water below the mixed layer and by vertical mixing. The mixing coefficients $K_{\mathrm{v}}$ were estimated from microstructure measurements, and on two of the cruises, $K_{\mathrm{v}}$ exceeded $1 \times 10^{-4} \mathrm{~m}^{2} / \mathrm{s}$, making the vertical mixing term of the same order of magnitude as the gas exchange and the upwelling term. In total, helium disequilibrium was observed on 54 stations. Of the calculated upwelling velocities, $48 \%$ were smaller than $1.0 \times 10^{-5} \mathrm{~m} / \mathrm{s}, 19 \%$ were between 1.0 and $2.0 \times 10^{-5} \mathrm{~m} / \mathrm{s}, 22 \%$ were between 2.0 and $4.0 \times 10^{-5} \mathrm{~m} / \mathrm{s}$, and on $11 \%$ of upwelling velocities exceeded this limit. The highest upwelling velocities were found in late June 2006. Meridional upwelling distribution indicated an equatorial asymmetry with higher vertical velocities between the equator and $1^{\circ}$ to $2^{\circ}$ south compared to north of the equator, particularly at $10^{\circ} \mathrm{W}$.

Associated heat flux into the mixed layer could be as high as $138 \mathrm{~W} / \mathrm{m}^{2}$, but this depends strongly on the chosen depths where the upwelled water comes from. By combining upwelling velocities with sea surface temperature and productivity distributions, a mean monthly equatorial upwelling rate of $19 \mathrm{~Sv}$ was estimated for June 2006 and a biweekly mean of $24 \mathrm{~Sv}$ was estimated for September 2005.

Citation: Rhein, M., M. Dengler, J. Sültenfuß, R. Hummels, S. Hüttl-Kabus, and B. Bourles (2010), Upwelling and associated heat flux in the equatorial Atlantic inferred from helium isotope disequilibrium, J. Geophys. Res., 115, C08021, doi:10.1029/2009JC005772.

\section{Introduction}

[2] Upwelling is known as one of the fundamental components of the meridional circulation of the equatorial Pacific and Atlantic since the pioneering investigations of Cromwell [1953], Knauss [1963], and Wyrtki [1981]. The so-called "tropical cells" are driven by the Ekman divergence of zonal winds causing vertical motion. In the upwelling regions of the tropical Atlantic, the thermocline is directly connected to the surface mixed layer and thus allows the exchange of biogeochemical properties between the thermocline and the atmosphere (e.g., exchange of $\mathrm{CO}_{2}$ ).

\footnotetext{
${ }^{1}$ Institut für Umweltphysik, Universität Bremen, Bremen, Germany.

${ }^{2}$ Leibniz Institut für Meereswissenschaften IFM-GEOMAR, Kiel, Germany.

${ }^{3}$ Now at Bundesamt für Seeschifffahrt und Hydrographie BSH, Hamburg, Germany.

${ }^{4}$ Universite de Toulouse, UPS (OMP-PCA), LEGOS, Toulouse, France.

${ }^{5}$ IRD, LEGOS, Cotonou, Benin.
}

Copyright 2010 by the American Geophysical Union. 0148-0227/10/2009JC005772
The upwelling regions are also high in biological activity because upwelled water brings nutrients into the euphotic zone.

[3] Early estimates of upwelling speeds above the equatorial undercurrent (EUC), based on displacement of isotherms, were a few meters per day, a value consistent with modern estimates. Direct measurements of upwelling have been hampered by the small speeds on scales of $10^{-5} \mathrm{~m} / \mathrm{s}$. Instead, vertical motion is estimated by indirect methods. In the equatorial belt, upwelling cannot be reasonably calculated by wind stress curl because of the vanishing Coriolis parameter. Most studies have tried to infer $w$ by calculating horizontal divergence of horizontal velocities in combination with the continuity equation using moored data, shipboard measurements, as well as drifter trajectories. From a yearlong deployment of current meters at the equator at $28^{\circ} \mathrm{W}$, Weingartner and Weisberg [1991a] inferred vertical velocities by integrating the continuity equation. The record-length averaged $w$ profile showed a maximum of $0.6 \times 10^{-5} \mathrm{~m} / \mathrm{s}$ above the core of the EUC. In general, the errors seem to be similar to the average vertical velocity [Helber and Weisberg, 2001; Weisberg and Qiao, 2000]. 


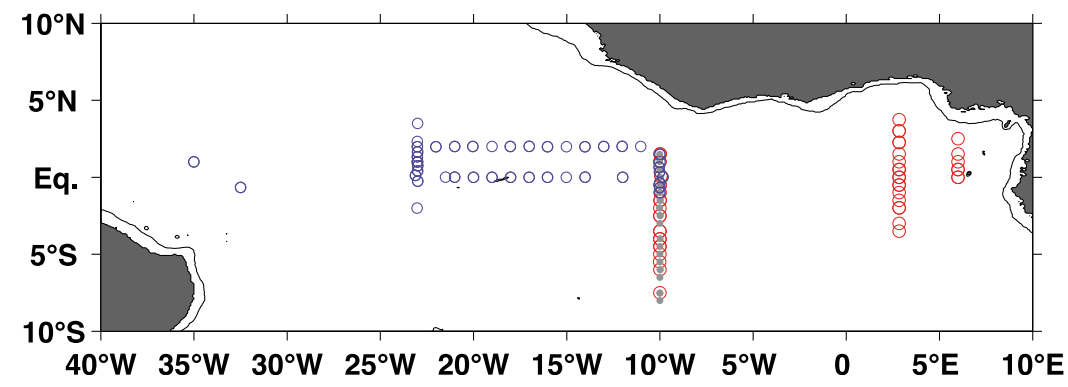

Figure 1. Conductivity temperature and depth stations with helium samples in the mixed layer: (red circles) cruise EGEE2, September 2005; (gray dots) cruise EGEE3, June 2006; and (blue circles) cruise M68/2, June 2006.

[4] Gouriou and Reverdin [1992] used data from cruises between 1982 and 1984, during which surface buoys were deployed, and profiles of horizontal velocity down to $500 \mathrm{~m}$ were collected using a profiling current meter. They determined an average vertical velocity at the base of mixed layer of 1 to $2 \times 10^{-5} \mathrm{~m} / \mathrm{s}$. Estimates of uncertainty were of the same order of magnitude.

[5] The effect of upwelling on the mixed layer heat balance is discussed controversially. While earlier observational studies claimed that vertical advection of heat due to upwelling causes the formation of the equatorial cold tongue in early summer [e.g., Weingartner and Weisberg, 1991b], more recent observational studies suggest that the heat flux due to vertical advection of cold water into the mixed layer is a minor term in the heat balance [e.g., Foltz et al., 2003]. Results from a recent modeling study, however, found some support for the earlier observational studies because they indicate that cooling due to vertical processes at the base of the mixed layer, i.e., vertical advection, diapycnal mixing, and entrainment, is dominantly balancing the net atmospheric mixed layer warming in the central and eastern equatorial Atlantic [Peter et al., 2006].

[6] Klein and Rhein [2004, hereafter KR04] proposed an approach to infer equatorial upwelling velocities by exploiting the helium isotope disequilibrium between the atmospheric and the equatorial oceanic mixed layer. Disequilibrium is generally found in upwelling areas because the upwelled water is higher in ${ }^{3} \mathrm{He}$ concentrations. This isotope is released into the interior of the oceans by hydrothermal venting [e.g., Lupton, 1998]. KR04 used data in the equatorial Atlantic at $9^{\circ} \mathrm{E}$ and $10^{\circ} \mathrm{W}$. Although the vertical and horizontal resolutions of the isotope data were rather coarse and not suitable for that purpose, their estimate for $w$ of $1.5 \times 10^{-5} \mathrm{~m} / \mathrm{s}$ was comparable to the few available results using other methods.

[7] In the framework of the German program "Surface Ocean Processes in the Anthropocene," helium isotope and hydrographic data were collected during two French cruises and one German cruise in the eastern tropical Atlantic. The
French cruises were carried out within the project, "Etude de la circulation océanique et des échanges océan-atmosphère dans le Golfe de Guinée" (EGEE) [Bourles et al., 2007]. Helium samples were collected during the NO Le Suroit cruise EGEE2 in September 2005 and during the $N O$ L'Atalante cruise EGEE3 in June 2006. Additional tracer samples are available from the FS Meteor cruise (M68/2) carried out quasi-simultaneously to the EGEE3 cruise in June 2006 (Figure 1 and Table 1). In total, approximately 500 helium samples from the upper water column (Table 1 and Figure 1) are available for this study, enabling applicability of the method of KR04 for the first time. In addition, microstructure profiles were collected on most of the helium sampling stations, which allows partitioning of helium fluxes in diapycnal and vertical advective fluxes.

\section{Measurements}

\subsection{Conductivity Temperature and Depth} Measurements and Helium Analysis

[8] Conductivity temperature and depth (CTD) profiles were collected using a Seabird SBE11 system on all cruises. Laboratory calibration of the temperature sensors and underway conductivity calibration using in situ water samples suggested that the accuracy of temperature and salinity was better than 0.003 . Helium isotopes were analyzed with the Bremen high-resolution static mass spectrometer (MAP 215-50, http://www.noblegas.uni-bremen.de). The system is capable of resolving ${ }^{3} \mathrm{He}$ from the mass -3 hydrogen species (HD and ${ }^{3} \mathrm{H}$ ) leaking from the metal walls. Two helium isotopes exist $\left({ }^{3} \mathrm{He}\right.$ and $\left.{ }^{4} \mathrm{He}\right)$, which have a slightly different solubility because of their difference in mass. The high stability of the analysis system usually provides a precision of less than $0.4 \%$ for the ${ }^{3} \mathrm{He} /{ }^{4} \mathrm{He}$ ratio [Sültenfu $\beta$ et al., 2009]. Because of minor technical problems, the precision for the ratios of data used here was $0.5 \%$. In this study, we quantified upwelling velocities from the ratio of the concentration of isotopes ${ }^{3} \mathrm{He}$ and ${ }^{4} \mathrm{He}$ and its deviation from the equilibrium ratio. Thus, an important parameter is the

Table 1. Helium Data

\begin{tabular}{lll}
\hline Cruise & \multicolumn{1}{c}{ Date } & \multicolumn{1}{c}{ Chief Scientist $^{\text {Helium Samples }^{\text {a }}}$} \\
\hline EGEE2 & 1-29 Sep 2005 & B. Bourles, IRD \\
EGEE3 & 24 May to 6 Jul 2006 & B. Bourles, IRD \\
M68/2 & 6 Jun to 9 Jul 2006 & P. Brandt, IFM-GEOMAR \\
\hline
\end{tabular}

${ }^{\mathrm{a}}$ Number of helium samples of the final data set. 
accuracy of the ${ }^{3} \mathrm{He} /{ }^{4} \mathrm{He}$ ratio, which is better than $0.01 \%$ for this data set. Concentrations of ${ }^{3} \mathrm{He}$ and ${ }^{4} \mathrm{He}$ are commonly reported as an isotopic ratio $\delta^{3} \mathrm{He}$, which is defined as the isotopic ratio of ${ }^{3} \mathrm{He}$ to ${ }^{4} \mathrm{He}$ in the water sample compared with the ratio in air:

$$
\delta^{3} \mathrm{He}(\%)=\frac{\left({ }^{3} \mathrm{He} /{ }^{4} \mathrm{He}\right)_{\text {water }}-\left({ }^{3} \mathrm{He} /{ }^{4} \mathrm{He}\right)_{\text {air }}}{\left({ }^{3} \mathrm{He} /{ }^{4} \mathrm{He}\right)_{\text {air }}} 100 .
$$

\subsection{Microstructure Measurements}

[9] Microstructure profiles from the surface to approximately $200 \mathrm{~m}$ in depth were collected during all three cruises (Table 1) using loosely tethered profilers manufactured by Sea \& Sun Technology (profiler MSS90-L during EGEE2 and M68/2 and profiler MSS90-D during EGEE3). Each profiler was equipped with two shear sensors (airfoil), a fast temperature sensor (FP07), acceleration and tilt sensors, as well as standard CTD sensors. All data are recorded at a rate of $1024 \mathrm{~Hz}$. A detailed description of the instruments is given in Prandke and Stips [1998]. Both profilers were adjusted to descend at 0.5 to $0.6 \mathrm{~m} / \mathrm{s}$. Sinking rates were only slightly reduced (by $<0.1 \mathrm{~m} / \mathrm{s}$ ) in regions of strong background shear such as within the EUC. Usually, three to eight microstructure profiles were collected at each CTD station, totaling in 640 profiles during the three cruises. Dissipation rates of turbulent kinetic energy $(\varepsilon)$ were determined from the airfoil shear data by integrating shear wave number spectra assuming isotropic turbulence as follows:

$$
\varepsilon=7.5 \mu \int_{k_{\min }}^{k_{\max }} E_{\mathrm{d} u^{\prime} / \mathrm{dz}}(k) \mathrm{d} k,
$$

where $\mu$ is the dynamic viscosity of seawater. Shear spectra $E_{\mathrm{du}{ }^{\prime}}{ }_{\mathrm{ddz}}(k)$ were calculated from $1 \mathrm{~s}$ ensembles (1024 values) and were integrated between a lower $k_{\min }=3 \mathrm{cpm}$ and an upper wave number $k_{\max }$ that varied between 14 and $30 \mathrm{cpm}$ depending on the Kolmogorov wave number. Loss of variance because of the limited wave number band was taken into account by fitting the observed shear spectra to the universal Nasmyth spectrum. Similarly, corrections for the loss of variance because of the finite sensor tip of the airfoil probes were applied. Noise levels of inferred $\varepsilon$ are below $1 \times 10^{-9} \mathrm{~W} / \mathrm{kg}$ for the MSS90-L profiler and less than $4 \times 10^{-10} \mathrm{~W} / \mathrm{kg}$ for MSS90-D profiler. Turbulent eddy coefficients for mass (eddy diffusivities) were estimated from the calculated dissipation rates of turbulent kinetic energy $(\varepsilon)$ using the Osborn [1980] relationship $K \rho=$ $\Gamma \varepsilon N^{-2}$. Here, $\Gamma$ is mixing efficiency and $N$ is buoyancy frequency.

\subsection{Remote Sensing Data}

[10] Upwelling is usually associated with the equatorial cold tongue and enhanced oceanic net primary production (NPP). Hence, data sets of sea surface temperature (SST) and NPP provide additional independent insights to upwelling intensity. Furthermore, wind speed is needed to calculate the helium air-sea gas exchange.

[11] In this contribution, daily fields of SST data using the Reynolds Optimum Interpolation data set (http://www.ncdc. noaa.gov/oa/climate/research/sst/griddata.php) [Reynolds et al., 2007] were analyzed. The data set has a spatial resolution of $0.25^{\circ}$ and combines the data of two satellite missions: advanced very high resolution radiometer infrared satellite SST data and advanced microwave scanning radiometer as well as in situ measurements from ships and buoys. The data are available from 1981 to present. Here, weekly means for the period of the cruises are presented.

[12] For an estimate of the oceanic production, the Ocean Productivity Standard Product (http://www.science. oregonstate.edu/ocean.productivity/index.php) has been chosen. The data set combines Moderate Resolution Imaging Spectroradiometer surface chlorophyll concentrations, Moderate Resolution Imaging Spectroradiometer SST data, and Sea-viewing Wide Field-of-view Sensor cloud-corrected incident daily photosynthetically active radiation. The calculation of the NPP uses the vertically generalized production model [Behrenfeld and Falkowski, 1997]. Data are available as $8 \mathrm{~d}$ averages from mid-2002 to present.

[13] Wind velocities used for the calculation of upwelling velocities are taken from the QuikSCAT MWF product distributed by Centre ERS d'Archivage et de Traitement (http:// www.ifremer.fr/cersat/products/gridded/mwf-quikscat/). The product provides daily, weekly, and monthly fields of wind stress and velocity as well as their SEs on a global $0.5^{\circ} \times$ $0.5^{\circ}$ grid. The data are available from August 1999 to present. In this study, we used weekly wind fields for September to October 2005 and from June to July 2006, covering the observational periods. In addition, for comparisons, Prediction and Research Moored Array in the Tropical Atlantic (PIRATA) [Bourles et al., 2008] buoy daily wind data from $0^{\circ} \mathrm{N}, 10^{\circ} \mathrm{W}$ were used (TAO Project Office; http://www. pmel.noaa.gov/tao/disdel/disdel-pir.html).

\section{Methods}

[14] Helium is a noble gas that is soluble in water and is exchanged between the oceanic mixed layer and the atmosphere by gas transfer. In general, the surface layer of the ocean is in solubility equilibrium with the atmosphere. The theoretical solubility equilibrium value of $\delta^{3} \mathrm{He}$ in the warm mixed layer of the tropical ocean is $-1.6 \%$, whereas for lower temperatures, the equilibrium value is shifting to $-1.8 \%$ [Weiss, 1970; Benson and Krause, 1980]. In general, one finds the equilibrium $\delta^{3} \mathrm{He}$ in the mixed layer outside the tropical ocean (KR04). In the equatorial band, however, a significant excess of $\delta^{3} \mathrm{He}$ is observed (Figure 2). This excess originates from waters of high $\delta^{3} \mathrm{He}$ found below the mixed layer, which obtain their elevated $\delta^{3} \mathrm{He}$ concentrations predominately from venting of primordial ${ }^{3} \mathrm{He}$ through hydrothermal activity.

[15] The observed $\delta^{3} \mathrm{He}$ disequilibria in the surface layer are solely maintained by vertical processes: upwelling and vertical mixing. Horizontal advection of equilibrated water in the mixed layer would assist the air-sea gas exchange in removing the disequilibrium. The production of ${ }^{3} \mathrm{He}$ in the mixed layer by radioactive decay of tritium is too small to maintain disequilibrium against the gas transfer (KR04). Like for oxygen, air bubbles injected into the water, which might partially or totally dissolve, will cause excess concentrations. However, because of the similar solubility of both helium isotopes, the increase in their concentration will 

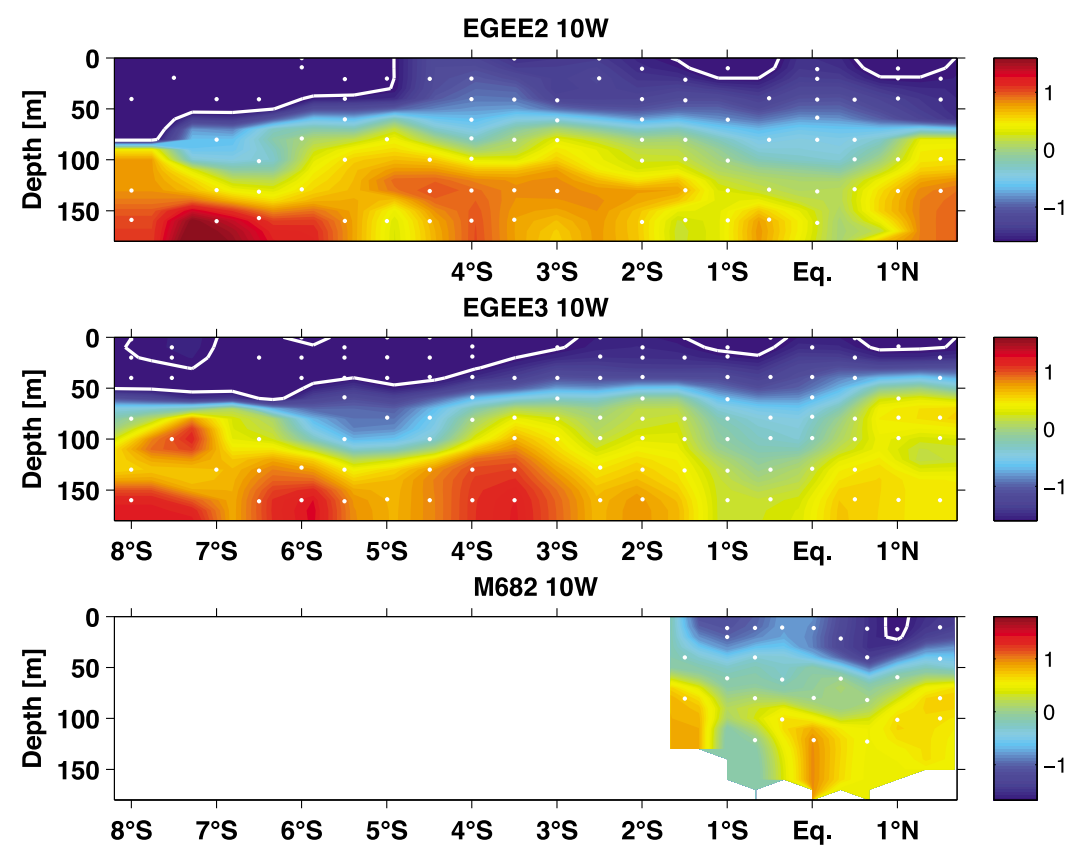

Figure 2. $\delta^{3} \mathrm{He}(\%)$ distributions at $10^{\circ} \mathrm{W}$ : (top) EGEE2, September 2005; (middle) EGEE3, June 2006; (bottom) $\mathrm{M} 68 / 2$, June 2006. The white lines follow $\delta^{3} \mathrm{He}(\%)=-1.6 \%$, the equilibrium ratio in surface water for tropical temperatures.

be similar and the $\delta^{3} \mathrm{He}$ ratio concentration in the mixed layer is thus unaltered.

[16] At first, we checked whether the one-dimensional model used by KR04 is still valid. KR04 assumed that the helium ratios in the mixed layer are determined by a balance between air-sea gas exchange and upwelling. Because of the lack of data, they neglected other potentially important processes, in particular vertical mixing and horizontal advection of helium because of lateral $\delta^{3} \mathrm{He}$ gradients below the mixed layer. KR04 assumed that the $\delta^{3} \mathrm{He}$ ratio is homogeneously distributed below the mixed layer.

[17] In this study, the extensive helium data set (Table 1) is used to estimate the horizontal $\delta^{3} \mathrm{He}$ gradients below the mixed layer, i.e., to assess whether horizontal advection has to be included into the calculations. The strongest current in the equatorial band is the EUC so that presumably the depth range of the EUC would be mostly affected by zonal gradients. In September 2005, the EUC at $10^{\circ} \mathrm{W}$ extended from the base of the mixed layer at approximately 40 to $150 \mathrm{~m}$ in depth (M. Dengler et al., Enhanced upper ocean mixing and turbulent heat flux in the equatorial Atlantic at $10^{\circ} \mathrm{W}$, submitted to Geophysical Research Letters, 2009). We chose the depth range between 45 and $145 \mathrm{~m}$ to calculate the section averages of $\delta^{3} \mathrm{He}$ and the averages for the whole data set (Table 2). For the region at and east of $10^{\circ} \mathrm{W}$, the section average $\delta^{3} \mathrm{He}$ ratios from the EGEE2 (September 2005), EGEE3 (June 2006), and M68/2 (July 2006) cruises are comparable and agree within the measurement precision. This suggests that the temporal variability of $\delta^{3} \mathrm{He}$ ratios in that depth range is negligible. The area between $22^{\circ} \mathrm{W}$ and $35^{\circ} \mathrm{W}$ exhibits a somewhat lower $\delta^{3} \mathrm{He}$ ratio, but it is not significantly different from the means further east $\left(\delta^{3} \mathrm{He}_{\mathrm{west}}=\right.$ $0.00 \% \pm 0.12 \%$ versus $\left.\delta^{3} \mathrm{He}_{\text {east }}=0.17 \% \pm 0.07 \%\right)$. This difference is most likely caused by the zonal inclination of the thermocline but is neglected in the following calcula- tions. During cruise EGEE3, helium samples were taken at $10^{\circ} \mathrm{W}$ only.

[18] Below the mixed layer, the standard deviation of the $\delta^{3} \mathrm{He}$ ratios determined from all water samples collected in the depth range between 45 and $145 \mathrm{~m}$ is close to the measurement precision of $0.5 \%$ (Table 2), making the presence of significant horizontal or temporal trends unlikely. On all three cruises, however, lower $\delta^{3}$ He values were observed near the equator (Figure 2). This minimum is caused by the deepening of the isopycnals in the presence of the EUC. During EGEE2 and EGEE3, the EUC was centered at $0.2^{\circ} \mathrm{S}$ and at $0.4^{\circ} \mathrm{S}$, whereas its meridional extent was 245 and $290 \mathrm{~km}$, respectively [Kolodziejczyk et al., $2009]$. Lower $\delta^{3} \mathrm{He}$ values are obvious in both of these regions compared with the surrounding waters (Figure 2 ). The mean $\delta^{3} \mathrm{He}$ between 45 and $145 \mathrm{~m}$ in the area between $1^{\circ} \mathrm{S}$

Table 2. Section Averages (45-145 $\mathrm{m}$ in Depth) of $\delta^{3} \mathrm{He}$ Ratios

\begin{tabular}{lcc}
\hline Cruise $\quad$ Section & No. of He Measurements & Mean $\delta^{3} \mathrm{He}(\%)$ \\
\hline EGEE2 $10^{\circ} \mathrm{W}$ & 42 & $0.15 \pm 0.60,{ }^{\mathrm{a}} \pm 0.09^{\mathrm{b}}$ \\
EGEE3 $10^{\circ} \mathrm{W}$ & 52 & $0.16 \pm 0.58,{ }^{\mathrm{a}} \pm 0.08^{\mathrm{b}}$ \\
$\mathrm{M} 68 / 210^{\circ} \mathrm{W}$ and east & 51 & $0.17 \pm 0.50,{ }^{\mathrm{a}} \pm 0.07^{\mathrm{b}}$ \\
$\mathrm{M} 68 / 2 \mathrm{West}$ of $22^{\circ} \mathrm{W}$ & 22 & $0.00 \pm 0.56,{ }^{\mathrm{a}} \pm 0.12^{\mathrm{b}}$ \\
EGEE23 $3^{\circ} \mathrm{E}$ & 32 & $0.19 \pm 0.28,{ }^{\mathrm{a}} \pm 0.05^{\mathrm{b}}$ \\
$\mathrm{M} 68 / 2$ Outside $1^{\circ} \mathrm{S}-0.5^{\circ} \mathrm{N}$ & 47 & $0.17 \pm 0.51,{ }^{\mathrm{a}} \pm 0.07^{\mathrm{b}}$ \\
$\mathrm{M} 68 / 21^{\circ} \mathrm{S}-0.5^{\circ} \mathrm{N}$ & 26 & $0.02 \pm 0.45,{ }^{\mathrm{a}} \pm 0.10^{\mathrm{b}}$ \\
EGEE2Outside $1^{\circ} \mathrm{S}-0.5^{\circ} \mathrm{N}$ & 59 & $0.18 \pm 0.49,{ }^{\mathrm{a}} \pm 0.06^{\mathrm{b}}$ \\
EGEE2 $1^{\circ} \mathrm{S}-0.5^{\circ} \mathrm{N}$ & 10 & $-0.10 \pm 0.50,{ }^{\mathrm{a}} \pm 0.15^{\mathrm{b}}$ \\
$\quad$ All outside & 158 & $0.17 \pm 0.05^{\mathrm{a}}$ \\
$1^{\circ} \mathrm{S}-0.5^{\circ} \mathrm{N}$ & 36 & $-0.01 \pm 0.09^{\mathrm{a}}$ \\
\hline
\end{tabular}

${ }^{\text {a }}$ Standard deviation of the $\delta^{3} \mathrm{He}$ ratios determined from water samples collected in the depth range between 45 and $145 \mathrm{~m}$ for the sections specified.

${ }^{\mathrm{b}}$ Standard deviation of the mean. For the M68/2 cruise, the relatively small number of measurements at $10^{\circ} \mathrm{W}(n=15)$ was combined with the measurements taken east of $10^{\circ} \mathrm{W}(n=36)$. 
and $0.5^{\circ} \mathrm{N}$ was comparable during the cruises EGEE2 $(-0.1 \% \pm 0.1 \%)$ and $\mathrm{M} 68 / 2(0.02 \% \pm 0.1 \%)$. The average of the EGEE3 cruise $(-0.4 \% \pm 0.3 \%)$ suffers from a small number of measurements collected within the EUC $(n=4)$. In the equatorial area between $1^{\circ} \mathrm{S}$ and $0.5^{\circ} \mathrm{N}$, the mean $\delta^{3} \mathrm{He}$ calculated from M68/2 and EGEE2 was -.01\%. Outside this region, the mean of all three cruises was found to be $0.17 \%$.

[19] In contrast to the interior, the mixed layer itself exhibits strong spatial $\delta^{3} \mathrm{He}$ variability, caused by the presence of water with and without upwelling. The $\delta^{3} \mathrm{He}$ ratio in the mixed layer might also change on timescales of several days, for instance, when upwelling stops and the disequilibrium vanishes due to the air-sea gas exchange. The gas exchange would need a few days to 1 week to equilibrate the surface $\delta^{3} \mathrm{He}$ after the upwelling ceased. We have no helium data to resolve such a short timescale. Even if helium samples were taken several times a week, they would be difficult to interpret: The helium sampling would have to be carried out in a Lagrangian way, which is not easily done in the presence of strong zonal velocities.

[20] Thus, we chose to (1) keep a steady state approach and (2) calculate the upwelling velocity for each profile without considering horizontal advection while assuming that the inferred vertical velocities are roughly representative of a weekly average. Advection in the surface layer is indirectly taken into account by assuming a westwardflowing South Equatorial Current (SEC). For the gas exchange calculation, the wind speeds are averaged over the zonal extension that the SEC might cover in 1 week $(100 \mathrm{~nm})$.

[21] For the calculation of the upwelling velocities, we used a model that consists of two boxes: A mixed layer box (box 1) representing the mixed layer and an interior box (box 2) below box 1 that supplies the upwelling of enriched $\delta^{3}$ He waters. We retained the one-dimensional approach but used different concentrations for box 2 , depending on the geographical latitude (between $1^{\circ} \mathrm{S}$ and $0.5^{\circ} \mathrm{N}$ and outside this region; see Table 2). It is assumed that box 2 is bound by the mixed layer and at $145 \mathrm{~m}$ in depth. Also, we retain the steady state approach $\left(\mathrm{d} \delta^{3} \mathrm{He} / \mathrm{d} t=0\right)$. The timescale involved is set by the gas exchange (several days). The steady state equation is as follows:

$$
0=F_{\mathrm{g}}+K_{\mathrm{v}} \frac{\mathrm{d} C}{\mathrm{~d} z}+w\left(C_{2}-C_{1}\right)
$$

The first term on the right side of (1) describes the gas exchange with the atmosphere, the second term characterizes the turbulent flux into the mixed layer, and the third term is the vertical advective $\delta^{3} \mathrm{He}$ flux associated with the upwelling.

[22] $C_{1}$ is the $\delta^{3} \mathrm{He}$ in the mixed layer. It is not necessary to solve equation (1) for ${ }^{3} \mathrm{He}$ and ${ }^{4} \mathrm{He}$ individually because ${ }^{4} \mathrm{He}$ is essentially constant. The depth of the mixed layer was calculated from the CTD data as the depth at which potential density is increased by $0.1 \mathrm{~kg} / \mathrm{m}^{3}$ relative to the surface value. At an individual station, one to three helium samples were collected in the mixed layer, and the $\delta^{3} \mathrm{He}$ ratio of the surface box $C_{1}$ is taken as the mean. On 39 stations, two or more helium samples were taken in the mixed layer, and the mean standard deviation of all sample pairs is $0.2 \%$.

[23] As suggested in Table 2 , the $\delta^{3}$ He ratio of box $2\left(C_{2}\right)$ is used as the mean of the data of all three cruises (Table 2). For the area between $1^{\circ} \mathrm{S}$ and $0.5^{\circ} \mathrm{N}$, a $\delta^{3} \mathrm{He}$ ratio of $-0.01 \%$ is adopted; for the area outside, $\delta^{3} \mathrm{He}$ of $0.17 \%$ is used. KR04 estimated $+0.5 \%$ from the much smaller data set $(<10$ samples) available at that time. A $\delta^{3} \mathrm{He}$ ratio of box 2 that is closer to the surface equilibrium ratio $(-1.6 \%)$ increases the required upwelling velocity provided that all other parameters remain constant.

[24] The gas exchange rate

$$
F_{\mathrm{g}}=v_{\mathrm{g}} \Delta^{*} C
$$

is calculated from the observed helium excess in the mixed layer $\Delta^{*} C=C_{1}-C_{\mathrm{eq}}$, where $C_{\mathrm{eq}}$ is $-1.6 \%$, and the gas transfer velocity $v_{\mathrm{g}}$, which is a function of wind speed and Schmidt number. To accommodate for the timescale involved, we used the weekly averaged QuikSCAT wind product for the week before the sampling date. To take into account the westward-flowing SEC, wind speeds were zonally averaged from the longitude of the sampling location to $2^{\circ}$ further to the east. The zonal and temporal variabilities in the weekly products are minor (Figure 3), and the change from 1 week to another is smaller than $1 \mathrm{~m} / \mathrm{s}$. These small temporal and spatial variabilities led to the fact that the wind speed used here is robust against the choices made.

[25] The gas transfer velocity is calculated as follows:

$$
\left.v_{\mathrm{g}}\right|_{\mathrm{av}}(\mathrm{cm} / \mathrm{h})=P u_{\mathrm{av}}^{2}(\mathrm{~m} / \mathrm{s}) \cdot(S c / 660)^{-0.5} .
$$

The gas exchange scaling parameter $P$ was adopted from Wanninkhof [1992] for steady winds. Judging from the daily PIRATA buoy wind data, the standard deviation of the daily wind velocities during 1 month is in the order of $1 \mathrm{~m} / \mathrm{s}$, so to use $P=0.31$ for steady winds instead of $P=0.39$ for averaged climatological winds seems justified. Furthermore, polynomial fits given by Wanninkhof [1992] and temperature of the mixed layer were used to calculate Schmidt number $S c$.

[26] Recently, excess radiocarbon inventories of the global ocean have been used to make new estimates of the scaling parameter $P$, adopting the quadratic dependence on wind velocity from Wanninkhof [1992]. Naegler et al. [2006] showed that $P$ cannot be constrained by the inventories alone but is also dependent on the chosen wind field. Their average $P$ for monthly mean winds was 0.32 . Sweeney et al. [2007] used excess radiocarbon inventories and the reanalysis wind fields and the reported $P=0.27$ from the National Centers for Environmental Prediction/National Center for Atmospheric Research, Boulder, Colorado. The gas transfer velocities are linearly dependent on $P$ [equation (3)], and an uncertainty of $\pm 10 \%$ was assumed for $v_{\mathrm{g}}$. The dominant uncertainty of the gas exchange rate $F_{\mathrm{g}}$, however, originates from the uncertainty of the mean $\delta^{3} \mathrm{He}$ ratio in the mixed layer which is $\pm 0.2 \%$, i.e., $30 \%$ of a typical observed helium excess in the mixed layer $\left(\Delta^{*} C\right)$ of $0.6 \%$. The relative error of $F_{\mathrm{g}}$ is calculated as $31 \%$.

[27] As noted previously, turbulent flux of the $\delta^{3} \mathrm{He}$ ratio into the mixed layer, the second term of equation (1), was estimated from microstructure shear data. Turbulent eddy 

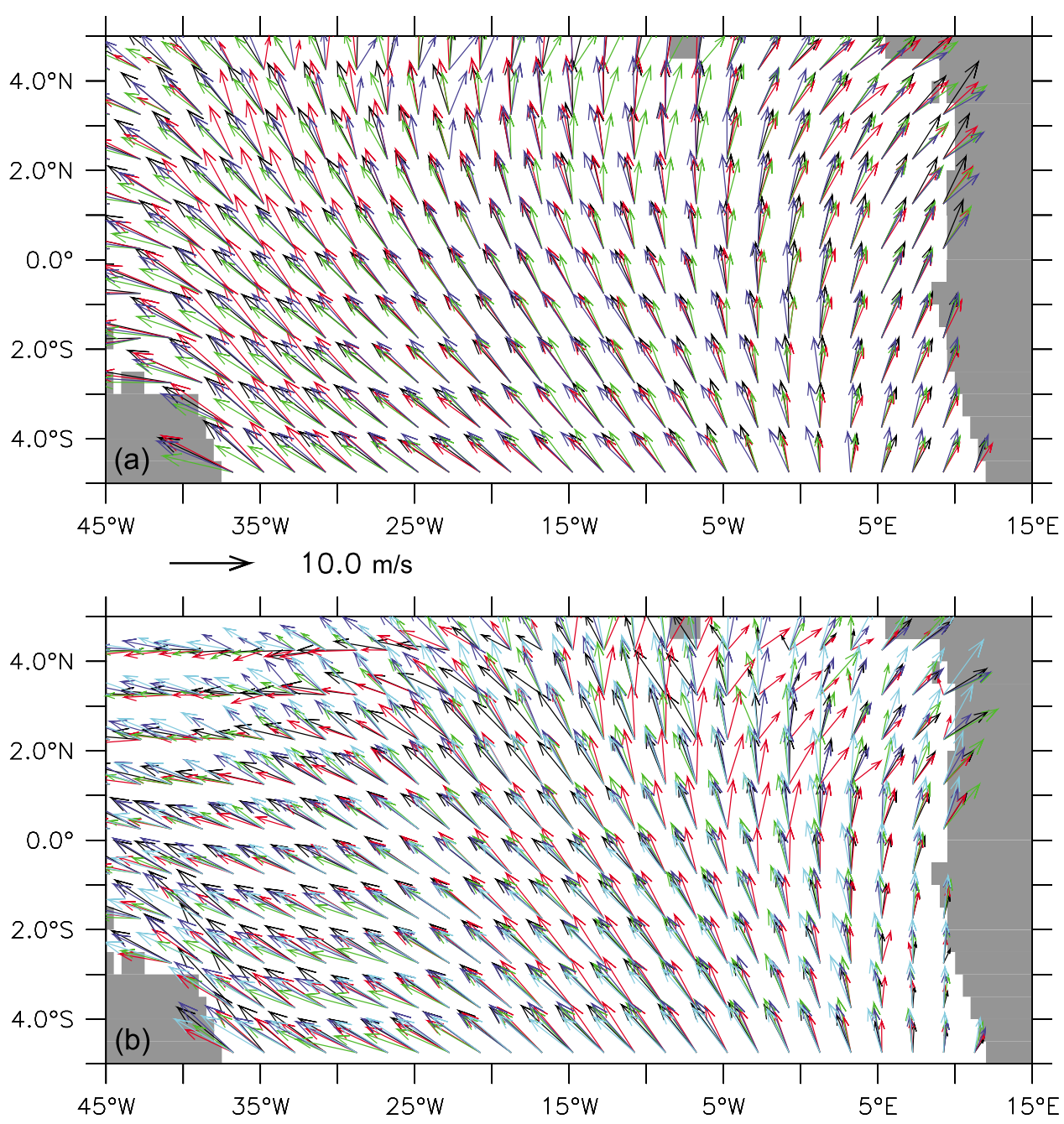

Figure 3. QuikSCAT weekly averaged wind speeds for consecutive weeks. (a) Period of EGEE2 cruise (September 2005): (black) 9-11 September, (red) 12-18 September, (green) 19-25 September, and (blue) 26 September to October. (b) Period of EGEE3 and M68/2 cruises (June 2006): (black) 29 May to 4 June 4, (red) 5-11 June, (green) 12-18 June, (blue) 19-25 June, and (cyan) 26 June to 3 July.

diffusivities $\left(K_{\rho}\right)$ were inferred from dissipation rates of turbulent kinetic energy $(\varepsilon)$ via $K_{\rho}=\Gamma \varepsilon N^{-2}$. Previous microstructure measurement programs in the equatorial Pacific [e.g., Peters et al., 1994] and a detailed analysis of the EGEE2 data (Dengler et al., submitted manuscript, 2009) have shown that mixing efficiency $\Gamma$ at the equator is smaller $(\sim 0.12)$ than in most other regions of the ocean $(0.2)$. Profiles of eddy diffusivities were thus calculated using the reduced $\Gamma$. Buoyancy frequency was determined from the least squared fits to salinity and temperature using a depth interval of $20 \mathrm{~m}$ in the deeper water column or less in the region close to the mixed layer. Eddy diffusivities were found to be strongly dependent on depth, decreasing from values as large as $1 \times 10^{-3} \mathrm{~m}^{2} / \mathrm{s}$ just below the mixed layer to $1 \times 10^{-5} \mathrm{~m}^{2} / \mathrm{s}$ in depths of 60 to $80 \mathrm{~m}$ (Figure 4). Mixing processes occurring at the equator are detailed in Dengler et al. (submitted manuscript, 2009). For calculating vertical $\delta^{3} \mathrm{He}$ fluxes, we assumed that the turbulent eddy diffusivity for mass $\left(K_{\rho}\right)$ equates vertical diffusivity $\left(K_{\mathrm{v}}\right)$ of $\delta^{3} \mathrm{He}$.
[28] Because of the long $\delta^{3} \mathrm{He}$ equilibrium timescale in the mixed layer, we were interested in obtaining the diapycnal flux averaged during a few days. Thus, section mean vertical diffusivity profiles were calculated by arithmetically averaging individual station profiles (Figure 4). Crucial for the mixed layer helium balance as used here is the vertical transport of helium due to turbulence through the transition layer between the interior and the mixed layers. A recent study of Johnston and Rudnick [2009] found this layer to be 8 to $24 \mathrm{~m}$ thick. The depth range and width of the thermocline were determined by computing the section average of the vertical temperature gradient determined at each station (from CTD profiles averaged on $10 \mathrm{~m}$ bins). The thermocline was chosen to be represented by the depth range, with an absolute vertical temperature gradient greater than $0.1^{\circ} \mathrm{C} / \mathrm{m}$ (Figure 4). With this definition, the mean thickness of the thermocline at $10^{\circ} \mathrm{W}$ was roughly $30 \mathrm{~m}$, i.e., slightly thicker than the transition layer of Johnston and Rudnick [2009]. For the turbulent flux calculation, the mean $K_{\mathrm{v}}$ values averaged over the thermocline depth range 


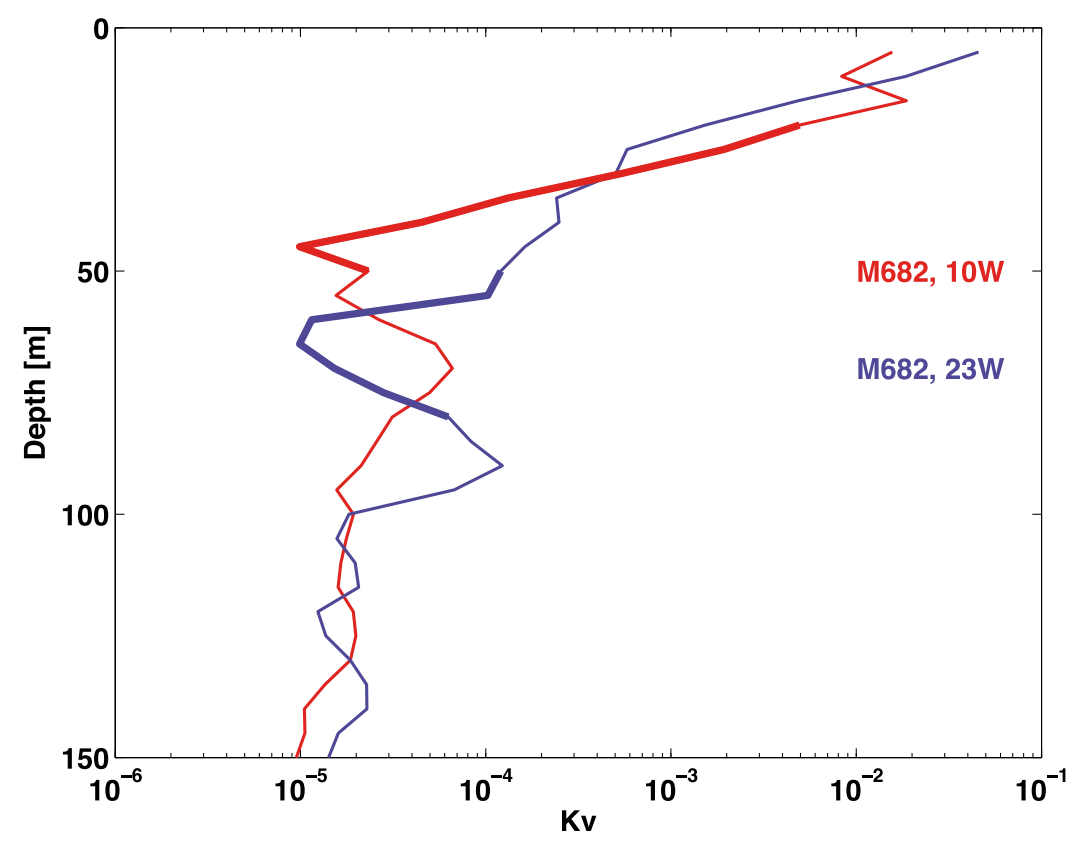

Figure 4. Section-averaged vertical turbulent mixing coefficient $K_{\mathrm{v}}\left(\mathrm{m}^{2} / \mathrm{s}\right)$, for $10^{\circ} \mathrm{W}$ and $23^{\circ} \mathrm{W}$, for the M68/2 cruise. The depth layer of the thermocline is indicated by the bold line.

were used, resulting in $K_{\mathrm{v}}\left(23^{\circ} \mathrm{W}\right)=5 \times 10^{-5} \mathrm{~m}^{2} / \mathrm{s}$ and $K_{\mathrm{v}}\left(10^{\circ} \mathrm{W}\right)=1 \times 10^{-3} \mathrm{~m}^{2} / \mathrm{s}$ during M68/2 (Figure 4). For the other two cruises (EGEE2 and 3 ), $K_{\mathrm{v}}$ profiles were available at the $10^{\circ} \mathrm{W}$ section (not shown). In September 2005, the mixing coefficient averaged over the depths of the thermocline was found to be $1.5 \times 10^{-4} \mathrm{~m}^{2} / \mathrm{s}$, and during the first week of June 2006 (EGEE3), $K_{\mathrm{v}}$ was much smaller $(5.4 \times$ $\left.10^{-6} \mathrm{~m}^{2} / \mathrm{s}\right)$. These coefficients are also adopted for stations not at $10^{\circ} \mathrm{W}$ of the respective cruise. The $\delta^{3} \mathrm{He}$ ratio gradient $\mathrm{d} C / \mathrm{d} z$ through the thermocline was calculated from profiles of all cruises by averaging the measurements $30 \mathrm{~m}$ above the thermocline and below the thermocline. The average vertical gradient $\mathrm{d} C / \mathrm{d} z$ resulted in $-0.96 \% / 65 \mathrm{~m}$.

[29] Whether turbulent mixing term plays an important role in the $\delta^{3} \mathrm{He}$ balance [equation (1)] largely depends on the magnitude of $K_{\mathrm{v}}$. For $K_{\mathrm{v}}>1 \times 10^{-4} \mathrm{~m}^{2} / \mathrm{s}$, upwelling velocities derived from (1) are reduced because of the elevated diapycnal flux of $\delta^{3} \mathrm{He}$ ratios from the deeper ocean

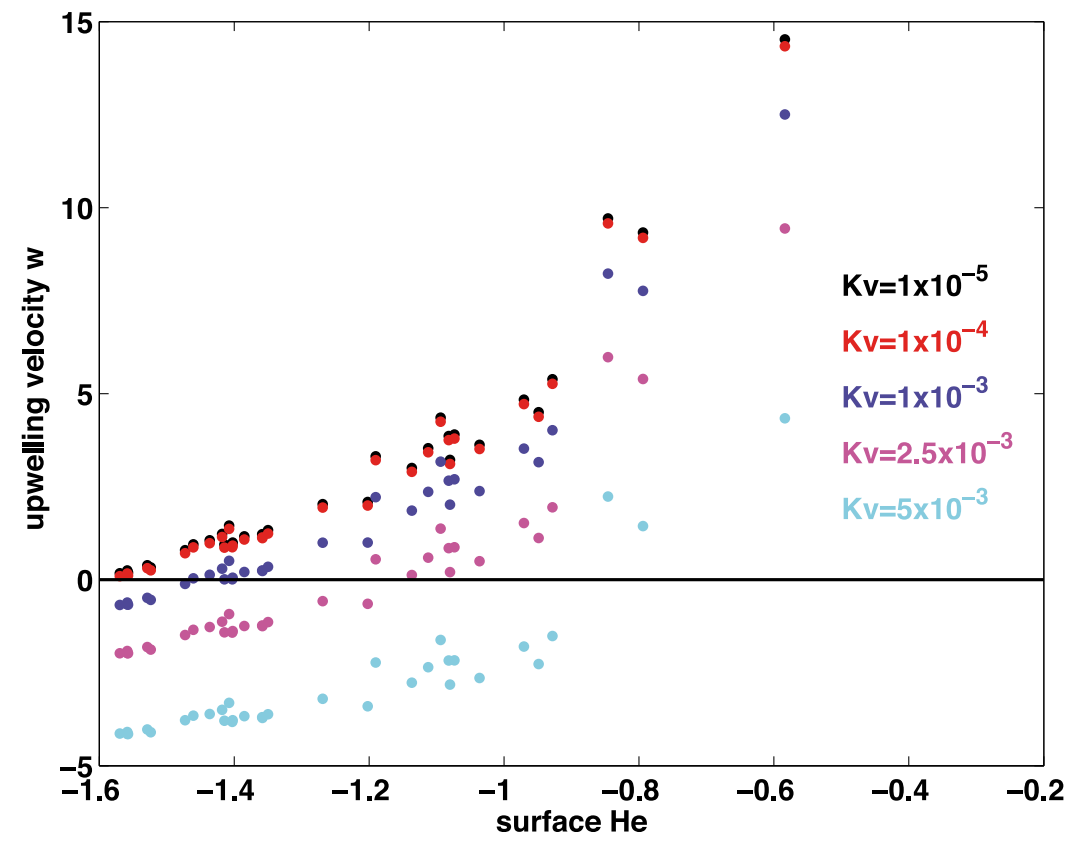

Figure 5. Upwelling velocities $w\left(\times 10^{-5} \mathrm{~m} / \mathrm{s}\right)$ for different helium isotope ratios in the mixed layer. $\delta^{3} \mathrm{He}=$ $-1.6 \%$ is the equilibrium value. Upwelling was calculated with vertical diffusivities $K_{\mathrm{v}}$ from $1 \times 10^{-5}$ to $5 \times 10^{-3} \mathrm{~m}^{2} / \mathrm{s}$. Negative $w$, downwelling; positive $w$, upwelling. Helium data are from cruise M68/2. 
Table 3. Upwelling Velocities

\begin{tabular}{lccc}
\hline Cruise & Stations Without Upwelling & Stations with Upwelling & Mean Upwelling Velocity $\left(\times 10^{-5} \mathrm{~m} / \mathrm{s}\right)$ \\
\hline EGEE2 & 17 & $16(48 \%)$ & $1.4 \pm 0.3$ \\
EGEE3 & 27 & $6(22 \%)$ & $0.6 \pm 0.3$ \\
M68/2 & 16 & $32(67 \%)$ & $2.6 \pm 0.6$ \\
\hline
\end{tabular}

${ }^{\mathrm{a}}$ Mean of the stations with a helium disequilibrium.

into the mixed layer (Figure 5). Vertical diffusivities exceeding $1 \times 10^{-3} \mathrm{~m}^{2} / \mathrm{s}$ were found to overcompensate the gas exchange term $F_{\mathrm{g}}$ and thus require a significant downwelling for mixed layer $\delta^{3} \mathrm{He}$ ratio concentrations less than $-1.4 \%$ (Figure 5). Because only means of $K_{\mathrm{v}}$ and $\delta^{3} \mathrm{He}$ ratios are involved, the uncertainty of the turbulent flux term was averaged to be approximately $\pm 10 \%$.

[30] The third term of equation (1) contains the unknown vertical velocity $w$ and the difference between the mean $\delta^{3} \mathrm{He}$ ratio in the mixed layer of an individual station and the mean $\delta^{3} \mathrm{He}$ ratio of box 2 . The uncertainty on the latter is small and not significantly dependent on the choice of the lower boundary of box 2 . Assuming that the upwelled water originates from the depth range from 45 to $100 \mathrm{~m}$ instead of from 45 to $145 \mathrm{~m}$, the mean $\delta^{3} \mathrm{He}$ would be $-0.05 \% \pm 0.5 \%$, with a standard deviation of the mean of $0.05 \%$. The calculated upwelling velocities are then smaller by $14 \%$ to $16 \%$ for $w<4 \times 10^{-5} \mathrm{~m} / \mathrm{s}$, by $19 \%$ for $w=6 \times 10^{-5} \mathrm{~m} / \mathrm{s}$, and by $23 \%$ for $w>8 \times 10^{-5} \mathrm{~m} / \mathrm{s}$. The largest uncertainty, however, is caused by the measurement uncertainty of the $\delta^{3} \mathrm{He}$ ratio of the surface layer. As mentioned before, the standard deviation of the mean mixed layer $\delta^{3} \mathrm{He}$ from two to three samples per station is $\pm 0.2 \%$; that is, a helium disequilibrium of $0.6 \%$ measured in the mixed layer may lead to an uncertainty of the upwelling velocity of approximately $30 \%$.

[31] The uncertainty of a single upwelling velocity is then approximately $\pm 47 \%$, i.e., in the same order of magnitude of the uncertainties reported from other methods. In calculating a section average, $w$ from the individual data somewhat reduces the uncertainties (Table 3 ). It is shown in the next section that the spatial and temporal distributions of the upwelling intensities are qualitatively comparable to weekly SST and chlorophyll distributions measured with satellites.

\section{Results and Discussion}

[32] Upwelling velocities were found to be roughly linearly dependant on the difference of the observed $\delta^{3} \mathrm{He}$ and the mixed layer equilibrium ratio of $-1.6 \%$ (Figure 5 ). Deviations from linearity are mainly caused by differences in wind speed. $\delta^{3} \mathrm{He}$ ratio disequilibria found in the mixed layer were as large as $1 \%$, leading to upwelling velocities greater than $10 \times 10^{-5} \mathrm{~m} / \mathrm{s}$ at that station. In total, helium disequilibrium was observed at 54 stations. Of the calculated upwelling velocities, $48 \%$ were smaller than $1.0 \times 10^{-5} \mathrm{~m} / \mathrm{s}$, $19 \%$ were between 1.0 and $2.0 \times 10^{5} \mathrm{~m} / \mathrm{s}$, and $22 \%$ were between 2.0 and $4.0 \times 10^{-5} \mathrm{~m} / \mathrm{s}$. During the EGEE2 (September 2005) and M68/2 (June-July 2006) cruises, 48\% and $67 \%$ of the stations with helium data in the surface layer show a disequilibrium with the atmosphere, and the mean inferred upwelling velocities are $1.4 \times 10^{-5}$ and $2.6 \times 10^{-5}$ $\mathrm{m} / \mathrm{s}$, respectively (Table 3 ). Only stations with upwelling have been considered in these calculations. When neglecting the observed vertical mixing coefficients and using $K_{\mathrm{v}}=1 \times$
$10^{-5} \mathrm{~m}^{2} / \mathrm{s}$ instead, the mean upwelling velocity for the M68/ 2 cruise increases from 2.6 to $3.4 \times 10^{-5} \mathrm{~m} / \mathrm{s}$.

[33] In May/June 2006 (cruise EGEE3), 22\% of the stations showed upwelling, and the estimated average velocity was $0.6 \times 10^{-5} \mathrm{~m} / \mathrm{s}$. The mean $w$ of all three cruises is closer to the higher end of published estimates. Contrary to previously reported upwelling velocities, the helium-derived estimates represent a weekly average, where most of the other reported estimates are climatological means [i.e., Grodsky and Carton, 2002; Broecker et al., 1978] or averaged in a $10^{\circ}$ latitude belt and zonally averaged [Meinen et $a l ., 2001]$ or are calculated from the divergence of current meter data or shipboard acoustic Doppler current profiler measurements [Weingartner and Weisberg, 1991a; Molinari et al., 2003], where the uncertainty is also considerable [Helber and Weisberg, 2001; Weisberg and Qiao, 2000].

[34] The $10^{\circ} \mathrm{W}$ section is the only region that was occupied during all three cruises (Figure 6). In September 2005, upwelling was found south of the equator and was strongest between $2^{\circ} \mathrm{S}$ and $5^{\circ} \mathrm{S}$. Similarly, elevated upwelling velocities south of the equator were inferred between $1^{\circ} \mathrm{S}$ and $3^{\circ} \mathrm{S}$ during early June 2006 (EGEE3) and between $1.5^{\circ} \mathrm{S}$ and the equator during late June 2006 (M68/2). A southward shift of maximum upwelling velocities can be explained by the presence of northward winds on the equator (Figure 3). Because of the vanishing of the Coriolis force, northward winds cause a northward surface flow on the equator that needs to be balanced by upwelling south of the equator. This "equatorial roll" has been previously observed in the Indian Ocean [e.g., Schott et al., 2002]. Models, however, have suggested that the equatorial roll should be present in the Atlantic and Pacific oceans as well [e.g., Jayne and Marotzke, 2001].

[35] When inspecting interannual variability, Hormann and Brandt [2009] found that the cold tongue in the upwelling season of 2005 was anomalously cold, suggesting that the upwelling velocities reported here might not be representative for a typical summer-fall situation. Marin et al. [2009], however, showed that while the SSTs in the cold tongue in June/July 2005 were colder compared with the SSTs in June/July 2006, the SST difference was mainly attributed to a time shift in the development of the cold tongue. In 2005, development of the cold tongue started in mid May, while in 2006, cooling within the cold tongue started in early June.

[36] The highest upwelling signal recorded in our data occurred during M68/2 (25 June to 7 July 2006), when upwelling is expected to be at its peak. Here, many stations with helium data were taken near the equator, where upwelling is assumed to be strongest. During M68/2, no helium data were collected south of $2^{\circ} \mathrm{S}$. Although the EGEE3 measurements were carried out only 3 weeks earlier (1-10 June 2006), the upwelling was much weaker and was focused near the equator. During June 2006, the QuikSCAT 


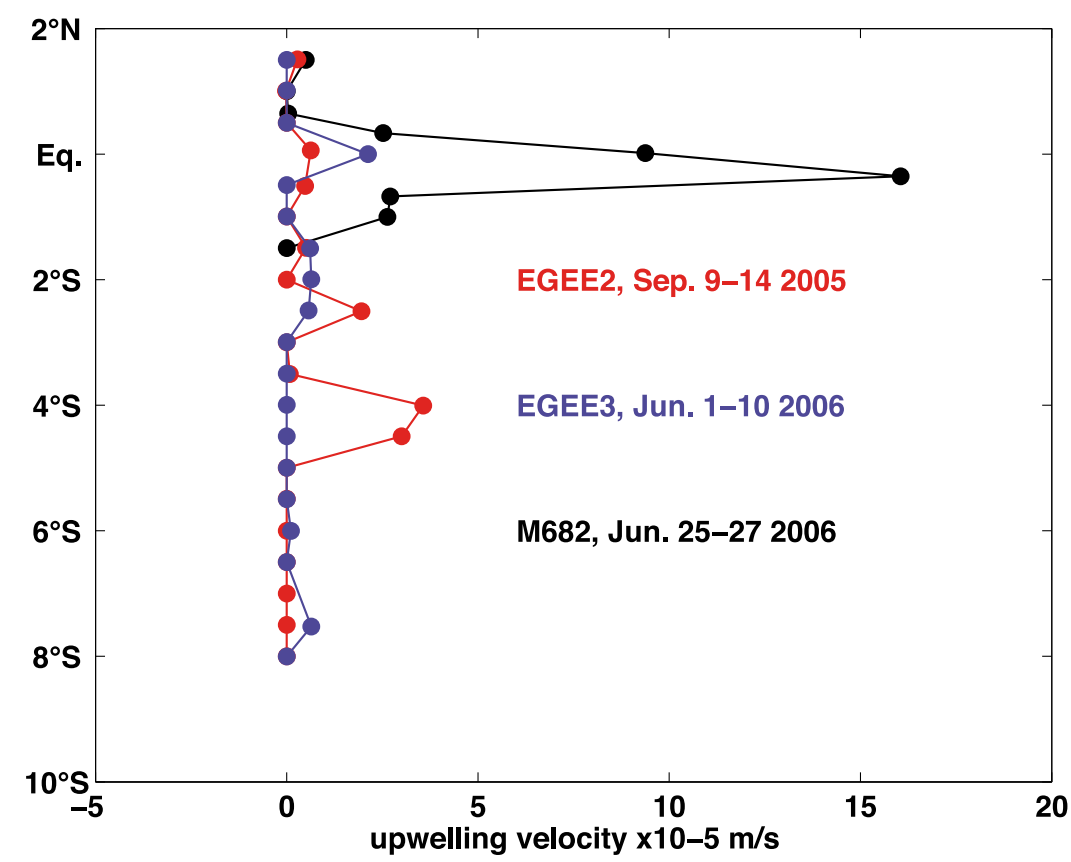

Figure 6. Upwelling velocity $\left(\times 10^{-5} \mathrm{~m} / \mathrm{s}\right)$ at $10^{\circ} \mathrm{W}$ for the three cruises. The M68/2 results were calculated using the observed averaged section mean of $K_{\mathrm{v}}=1 \times 10^{-3} \mathrm{~m}^{2} / \mathrm{s}$; on the two other data sets, a vertical mixing coefficient of $5 \times 10^{-5} \mathrm{~m}^{2} / \mathrm{s}$ was applied.

mean wind speeds $(6.6 \mathrm{~m} / \mathrm{s})$ were about $17 \%$ higher than the climatological mean, and this was confirmed by direct shipboard measurements and by the instruments on the PIRATA buoy at $0^{\circ} \mathrm{N}, 10^{\circ} \mathrm{W}$. No significant difference in mean weekly absolute or zonal wind speed, however, was found in the QuikSCAT winds between the periods when the $10^{\circ} \mathrm{W}$ section was occupied during EGEE3 (1-10 June 2006) and M68/2 (25-27 June 2006). Shipboard wind measurements and winds from the PIRATA buoy at $0^{\circ} \mathrm{N}$ measured winds exceeding $8 \mathrm{~m} / \mathrm{s}$ during 26-29 June 2006 , i.e., the M68/2 occupation of $10^{\circ} \mathrm{W}$, while during $1-10$ June 2006 (EGEE3), the PIRATA winds were lower by $25 \%$. Averaging during the whole month, the mean PIRATA wind speeds $(6.4 \mathrm{~m} / \mathrm{s})$ were similar to the QuikSCAT winds $(6.6 \mathrm{~m} / \mathrm{s})$.

[37] From the upwelling velocities, heat flux of the mixed layer due to the entrainment of cold water from below was estimated from $Q_{\mathrm{w}}=-\rho_{0} c_{\mathrm{p}} \Delta T w$. Here, $c_{\mathrm{p}}$ is heat capacity and $\rho_{0}$ is the density of seawater. The appropriate temperature difference $\Delta T$ at the base of the mixed layer is difficult to specify a priori. Considering the fact that the upwelling velocities $(w)$ determined here are averaged vertical velocities from about $90 \mathrm{~m}$ in depth, the center of box 2 , to the mixed layer, $\Delta T$ should reflect the temperature difference between the water that is essentially upwelled into the mixed layer and the water in the mixed layer. Previous studies on data in the equatorial Pacific have used the difference of temperature $20 \mathrm{~m}$ below the mixed layer and the mixed layer [e.g., Hayes et al., 1991], which resulted from linear regressing $\rho_{0} c_{\mathrm{p}} w$ against the heat content variability of the mixed layer. On the other hand, Johnston and Rudnick [2009] recently studied several 10,000 SeaSor temperature and salinity profiles and found the interface between the base of the mixed layer and the stratified interior to be 11 to
$24 \mathrm{~m}$ thick. To calculate the heat flux through this transition layer, one would need the temperature at the base of the mixed layer and the temperature below this transition zone. Johnston and Rudnick suggested two possible parameterizations of the transition layer thickness: one is a constant thickness between 11 and $24 \mathrm{~m}$ and one is a linear function of the mixed layer depth. The mixed layer at the periods of strong upwelling was shallow $(20-30 \mathrm{~m})$, so here we adopt a minimum transition layer thickness of $10 \mathrm{~m}$ in depth and determine $\mathrm{T}$ from the difference of temperature $10 \mathrm{~m}$ below the mixed layer base and the average mixed layer temperatures.

[38] Time series of temperature distributions and mixed layer depths were obtained by the PIRATA mooring at $0^{\circ} \mathrm{N}$, $10^{\circ} \mathrm{W}$. The corresponding upwelling velocity $(w)$ was calculated by averaging the velocities between $1.5^{\circ} \mathrm{N}$ and $1.5^{\circ} \mathrm{S}$ at $10^{\circ} \mathrm{W}$ in the appropriate period. The heat flux calculated from the data collected during EGEE2 (September 2005) and EGEE3 (May-June 2006) cruises yielded $Q_{\mathrm{w}}=23$ and $12 \mathrm{~W} / \mathrm{m}^{2}$, respectively. However, a rather elevated mean heat flux of $Q_{\mathrm{w}}=138 \mathrm{~W} / \mathrm{m}^{2}$ was determined for late June 2006 from the data collected at $10^{\circ} \mathrm{W}$ during M68/2, when maximum upwelling velocities were observed (Figure 6) and stronger winds relative to climatology occurred at the equator.

[39] This result suggests that entrainment of cold water into the mixed layer may indeed be a significant term in the mixed layer heat budget during the formation of the cold tongue when stronger winds occur at the equator. Foltz et al. [2003] studied the seasonal mixed layer heat budget in the tropical Atlantic and found a missing source of cooling of about $100 \mathrm{~W} / \mathrm{m}^{2}$ during May-July in the region of the cold tongue at $0^{\circ} \mathrm{N}, 10^{\circ} \mathrm{W}$, which they attributed, among others, to an underestimation of upwelling. Upwelling velocities 

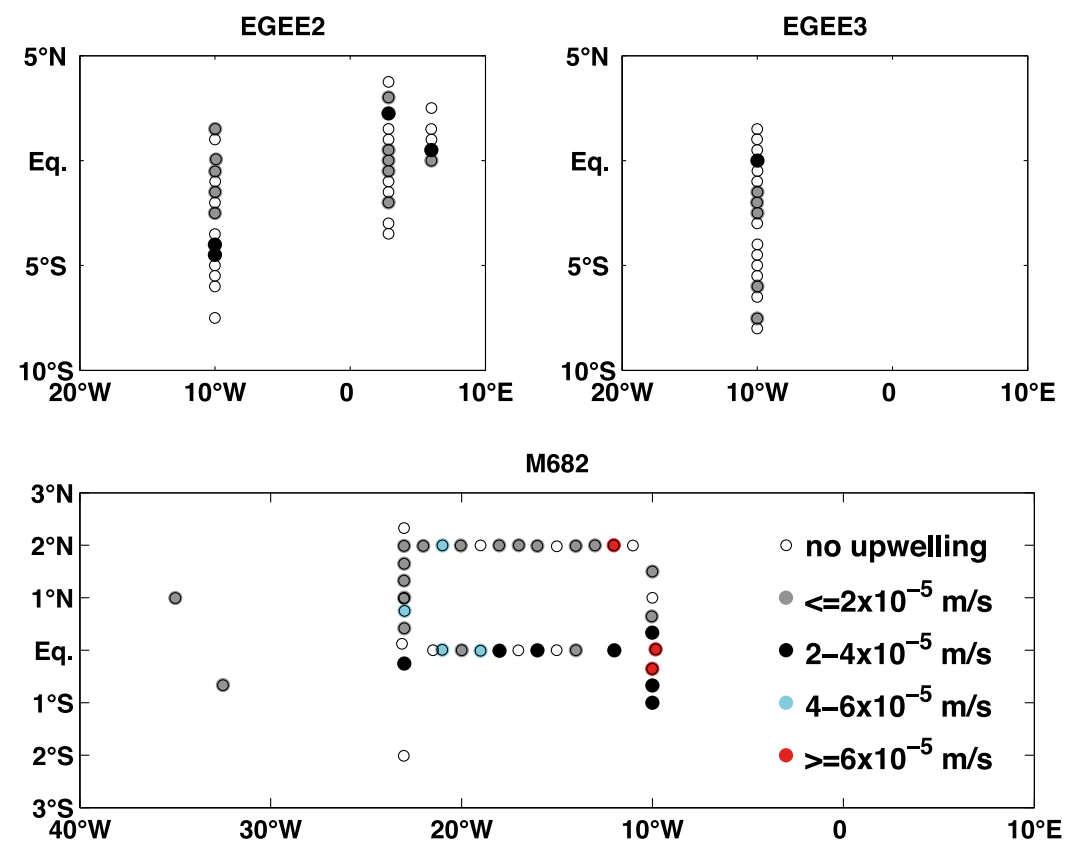

Figure 7. Upwelling velocity $w$ for (left) cruise EGEE2, September 2005, (right) cruise EGEE3, June 2006, and (bottom) cruise M68/2, June 2006.

and related heat fluxes determined by Foltz et al. [2003] were of the same order of magnitude as found here during September 2005 and May-June 2006 (EGEE2 and EGEE3), but their analysis lacked strong upwelling events and associated heat flux as determined previously for late June 2006. In their analysis, vertically velocities were determined from the divergence of horizontal surface currents from a drifter climatology that relies on temporal and spatial averaging. Stronger short-term upwelling events may thus be filtered out, and the effect of upwelling is underestimated. It should be noted that part of the missing cooling source of Foltz et $a l$. [2003] can also be explained by diapycnal heat fluxes caused by the strong turbulent mixing that was ignored in their study. For instance, a diapycnal heat flux of $55 \mathrm{~W} / \mathrm{m}^{2}$ was reported by Dengler et al. (submitted manuscript, 2009) for the September 2005 cruise.

[40] The inferred upwelling velocities from all three cruises are summarized in Figure 7. Most of the measurements focused on the equatorial band so that they cannot be compared with the upwelling rates calculated from the wind stress curl. We therefore compared our results qualitatively with the weekly mean SST (Figures 8a and 9a) and NPP distributions (Figures $8 \mathrm{~b}$ and $9 \mathrm{~b}$ ). In the tropical areas, solar radiation is not a limiting factor, and the availability of nutrients determines the productivity. The nutrient flux into the mixed layer is caused by equatorial upwelling. Thus, NPP and chlorophyll data are strongly linked to the upwelling intensity [Longhurst, 1993; Grodsky et al., 2008]. In September 2005 , the $10^{\circ} \mathrm{W}$ section shows coldest SST and highest productivity south of the equator, resembling the distribution of the upwelling velocity, and upwelling intensity was considerable in September 2005. The SST at $3^{\circ} \mathrm{E}$ was colder at that time (Figure 8a) than during the measurements in June 2006 (Figure 9a). In June 2006, the SST along the $2^{\circ} \mathrm{N}$ section are warmer than at $10^{\circ} \mathrm{W}$ and along the equator, a feature that is also reflected in the generally lower upwelling velocities at $2^{\circ} \mathrm{N}$ and in the lower productivities (Figure $9 \mathrm{~b}$ ). At $2^{\circ} \mathrm{N}$, the SST shows the typical signature of a tropical instability wave [e.g., Willett et al., 2006], and the colder temperatures at $2^{\circ} \mathrm{N}$ are at locations with higher upwelling velocities. The high upwelling speeds near the equator at $10^{\circ} \mathrm{W}$ also coincide with colder SSTs. The relation between cold SST and upwelling velocity holds for the weekly averaged SST but, in general, not for the temperature measured directly during the time of the helium sampling. The processes determining the actual SST have a much smaller timescale than the air-sea gas exchange, the dominating timescale of the surface helium ratios. Besides diapycnal processes, advection and surface fluxes are important for the heat balance in the mixed layer.

[41] Although being far from perfect, we tentatively use the observed linkage between upwelling and weekly averaged SST distributions to make a rough estimate of the upwelling rates. From the weekly SST distributions (Figures 9a and 10a), the areas with upwelling are calculated. The upwelling areas were assumed to have SSTs $<26.0^{\circ} \mathrm{C}$, and only regions between $4^{\circ} \mathrm{S}-4^{\circ} \mathrm{N}$ and $35^{\circ} \mathrm{W}-6^{\circ} \mathrm{E}$ were considered (Table 4). The corresponding upwelling velocity was calculated by averaging the nonzero upwelling velocities from that period. We did not include the location with zero upwelling velocities because, by the afore mentioned assumption, they did not belong to an area with mean weekly SST $<26^{\circ} \mathrm{C}$. The estimates of the upwelling transports are summarized in Table 4. As expected, when looking at the SST distributions and the upwelling intensity, the upwelling transports for the EGEE3 period (3 Sv) were much smaller than those during M68/2 (35 Sv). Assuming that the EGEE3 results are representative for the first 2 weeks and the M68/2 for the last 2 weeks of June 2006, a mean monthly upwelling transport of $19 \pm 7 \mathrm{~Sv}$ is calcu- 

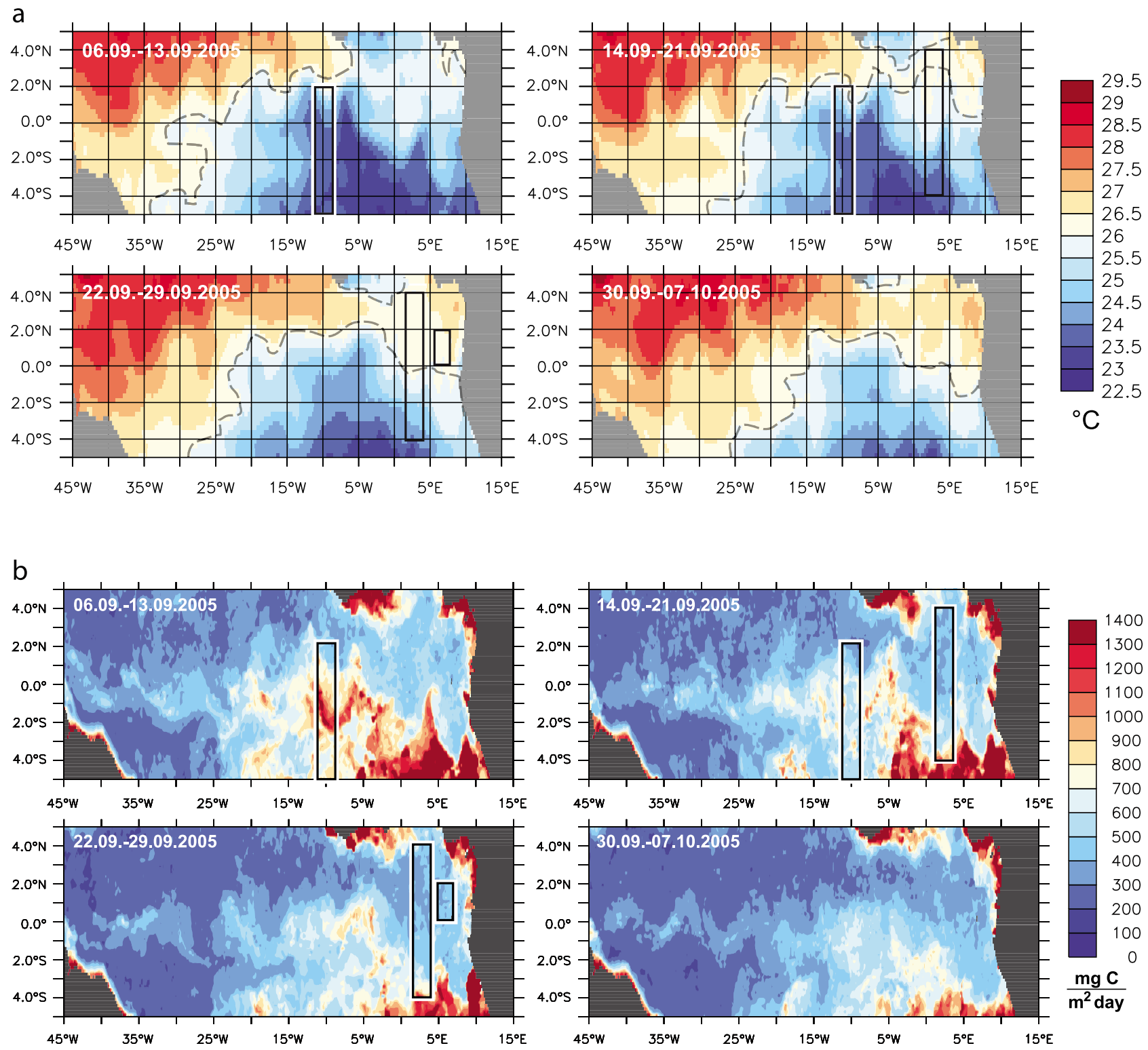

Figure 8. (a) Weekly averaged SST for September 2005. The black lines denote the time and location of the upwelling velocities estimates during cruise EGEE2. The dashed gray lines enclose the areas with temperatures cooler than $26^{\circ} \mathrm{C}$. (b) Weekly averaged productivity for September 2005. The black lines denote the time and location of the upwelling velocities estimates during cruise EGEE2. For better visibility on some of the subplots, the black lines are framed by white lines.

lated. The estimates (Table 4) are in the range of other reported values for the tropical Atlantic. Gouriou and Reverdin [1992] estimated $23 \mathrm{~Sv}$ for the upwelling season in the equatorial domain $\left(3^{\circ}\right.$ wide, $40^{\circ}$ longitude band) and an annual mean of 11 to $12 \mathrm{~Sv}$, with a large range of uncertainty because of the method and the limited data. Broecker et al. [1978] used the radiocarbon distribution to infer an annual rate of roughly $17 \mathrm{~Sv}$.

\section{Summary and Conclusions}

[42] Upwelling velocities $w$ in the equatorial band $\left(4^{\circ} \mathrm{S}-\right.$ $4^{\circ} \mathrm{N}$ ) are too small to be directly observed. Therefore, other methods are required. Most studies have tried to infer $w$ by using horizontal divergence in combination with the continuity equation using moored data, shipboard measurements, and drifter trajectories. KR04 proposed a new method, i.e., to calculate upwelling from helium disequilibria in the mixed layer. Here, we showed that this method is uniquely suitable to calculate upwelling velocities that, because of the timescale of the air-sea gas exchange, represent weekly averages. The absence of significant horizontal helium gradients even in the depth range of the EUC allowed the use of a one-dimensional two-box model, where the helium air-sea gas exchange is balanced by upwelling from heliumrich water below the mixed layer and by vertical mixing. 
a
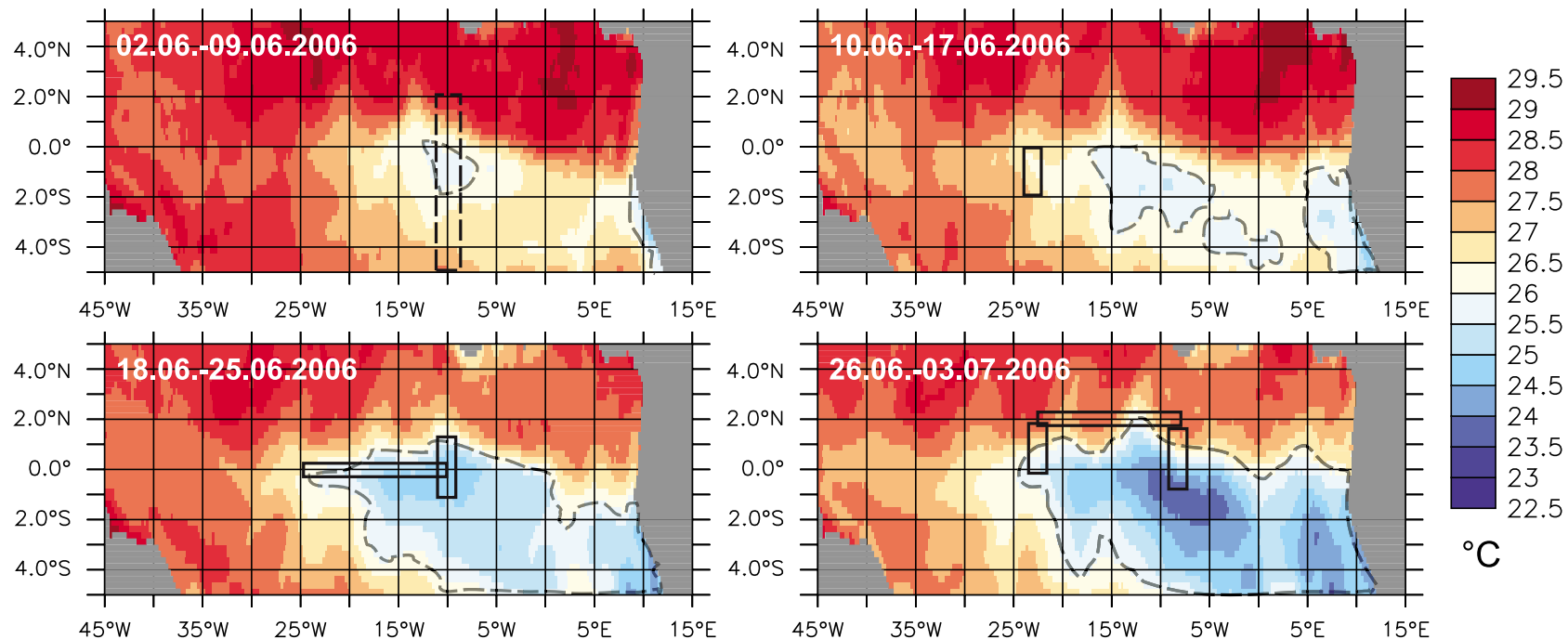

b
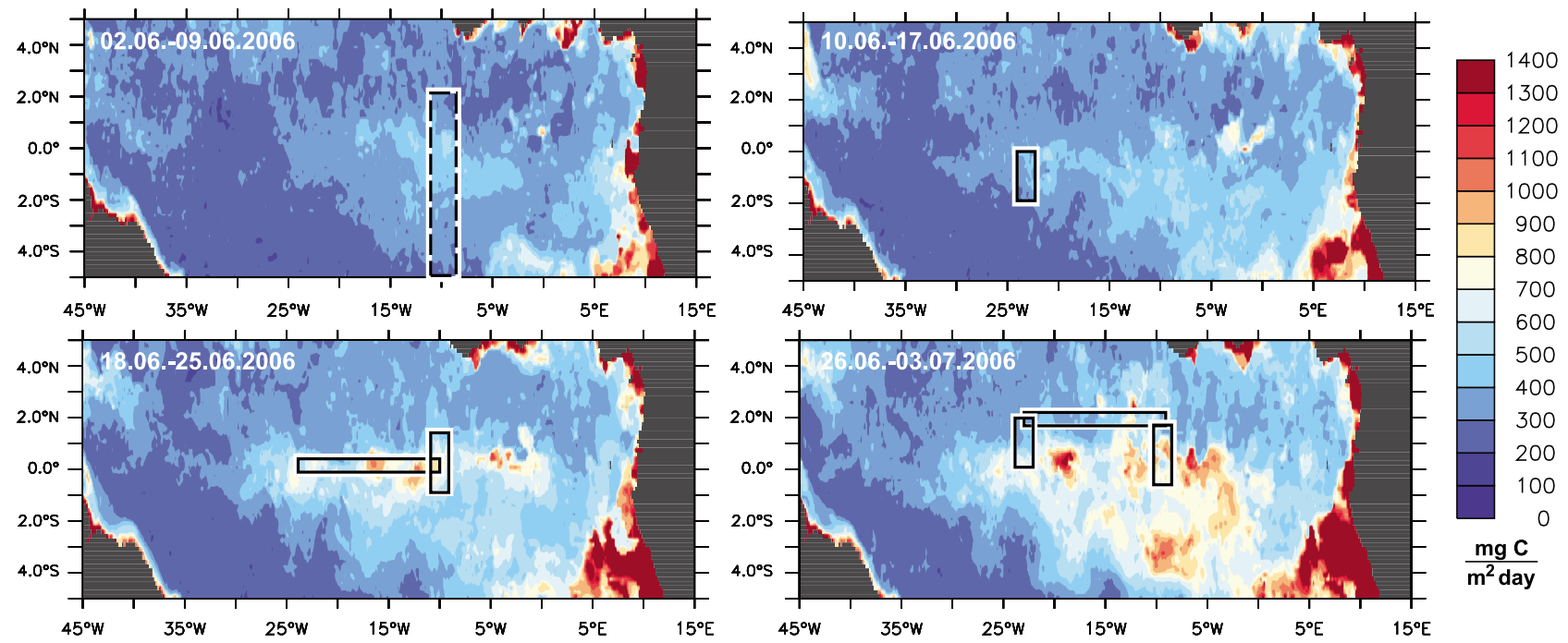

Figure 9. (a) Weekly averaged SST for the weeks from 2 June to 17 July 2006, the period for the EGEE3 and M68/2 cruises. The black lines denote location and time of estimates of upwelling velocities; dashed lines, EGEE3; bold lines, M68/2. The dashed gray lines enclose the area with temperatures cooler than $26^{\circ} \mathrm{C}$. (b) Weekly averaged productivity for the period of EGEE3 and M68/2 cruises. For better visibility, the black lines are framed with white on some of the subplots in Figure 9b.

Turbulent eddy diffusivities $K_{\mathrm{v}}$ were estimated from microstructure shear data. On two cruises, $K_{\mathrm{v}}$ in the thermocline exceeded $1 \times 10^{-4} \mathrm{~m}^{2} / \mathrm{s}$, suggesting that $\delta^{3} \mathrm{He}$ ratio fluxes due to vertical mixing are in the same order of magnitude as the air-sea gas exchange term. The wind field in the tropical Atlantic is steady, with small zonal and temporal gradients, so that the wind speed used to calculate the gas exchange flux is insensitive to the chosen zonal and temporal averaging, and the parameterization for steady winds by Wanninkhof [1992] is applicable.

[43] Upwelling velocities were found to be roughly linearly dependent on the $\delta^{3} \mathrm{He}$ ratio difference between the surface concentration and the mixed layer equilibrium ratio of $-1.6 \%$. The main uncertainty is the precision of the helium analysis of $\pm 0.5 \%$, and the total uncertainty of the calculated upwelling velocity was estimated to be $42 \%$.

Table 4. Upwelling Transport

\begin{tabular}{llc}
\hline Cruise & \multicolumn{1}{c}{ Period } & Upwelling Area $\left(\mathrm{m}^{2}\right)$ \\
\hline EGEE2 & 6-21 Sep 2005 & $1.7 \times 10^{12}$ \\
EGEE3 & 2-17 Jun 2006 & $4.1 \times 10^{11}$ \\
M68/2 & 18 Jun to 3 Jul 2006 & $1.4 \times 10^{12}$ \\
\hline
\end{tabular}


Below the mixed layer, the $\delta^{3} \mathrm{He}$ ratios do not show significant horizontal or temporal trends outside the EUC, which allowed to average all measurements below the mixed layer together and thus minimize the uncertainty of the mean $\delta^{3} \mathrm{He}$ ratio. The relatively small spatial and temporal $\delta^{3} \mathrm{He}$ gradients in and below the thermocline help to concentrate follow-up sampling efforts to the mixed layer. Uncertainties of inferred upwelling rates can be significantly reduced by taking more samples at a single location.

[44] During EGEE2 (September 2005) and M68/2 (JuneJuly 2006) cruises, $48 \%$ and $67 \%$ of the stations with helium data in the surface layer show a disequilibrium with the atmosphere, and the mean inferred upwelling velocities are $1.4 \times 10^{-5}$ and $2.6 \times 10^{-5} \mathrm{~m} / \mathrm{s}$, respectively. In the May/June 2006 cruise (EGEE3), 22\% of the stations showed upwelling, and the mean of those estimates was $0.6 \times 10^{-5} \mathrm{~m} / \mathrm{s}$. The overall mean $w$ of all three cruises resulted in $2.0 \pm$ $0.3 \times 10^{-5} \mathrm{~m} / \mathrm{s}$, which is closer to the higher end of published estimates.

[45] The resulting distribution of upwelling velocities suggests that upwelling is not symmetric about the equator but that higher upwelling velocities are found in the region between the equator and about $2^{\circ}$ south compared with same region north of the equator. This phenomenon can be explained by northerly winds on the equator, which cause a northward surface current because of the vanishing of the Coriolis force, which, in turn, causes divergence in the surface layer and thus stronger upwelling south of the equator. In the Indian Ocean, this surface flow is balanced by a southward return flow at 60 to $80 \mathrm{~m}$ in depth [Schott et al., 2002]. If a similar balance were achieved in the tropical Atlantic, a considerable meridional heat flux would be associated with this circulation cell.

[46] Mixed layer heat flux estimates due to upwelling are very sensitive to the choice of the temperature difference. When the difference between the mean temperature in the mixed layer and the temperature $10 \mathrm{~m}$ below the base of the mixed layer is used, the mean heat fluxes due to upwelling are calculated as $138 \mathrm{~W} / \mathrm{m}^{2}$ for late June $2006,12 \mathrm{~W} / \mathrm{m}^{2}$ for May/June 2006, and $23 \mathrm{~W} / \mathrm{m}^{2}$ for September 2005. The fluxes are comparable to the diapycnal heat fluxes (Dengler et al., submitted manuscript, 2009), suggesting that both fluxes are important components of the mixed layer heat budget in the equatorial eastern Atlantic.

[47] We used the combined observations of helium and weekly SST and productivity distributions to infer a mean monthly equatorial upwelling rate of 19 Sv for June 2006, with most of the upwelling taking place in the second half of the month. In September 2005, a biweekly mean of $24 \mathrm{~Sv}$ was calculated. To improve these estimates would require a larger measurement campaign, with increased number of helium samples in the mixed layer combined with microstructure measurements.

[48] Acknowledgments. This work is part of the German project Surface Ocean Processes in the Anthropocene and is supported by the German Ministry for Education and Research, BMBF, grant 03F0462D (M. Rhein). Funding for the microstructure measurement program was provided by the Deutsche Forschungsgemeinschaft as part of the Emmy Noether Program grant DE1369/1-1 (M. Dengler). "Etude de la circulation océanique et des échanges océan-atmosphère dans le Golfe de Guinée" is the French oceanic contribution to the international African Monsoon Multidisciplinary Analysis program (http://www.amma-international.org). Informa- tion on the EGEE cruises is summarized at http://www.brest.ird.fr/ actualites/EGEE.htm. The EGEE data can be found at http://database. amma-international.org. Information on the METEOR cruise M68/2 is available at http://www.ifm.zmaw.de/de/leitstelle/reisen-des-fs-meteor/.

\section{References}

Behrenfeld, M. J., and P. G. Falkowski (1997), Photosynthetic rates derived from satellite-based chlorophyll concentration, Limnol. Oceanogr., 42, $1-20$.

Benson, B. B., and D. Krause Jr. (1980), Isotopic fractionation of helium during solution: A probe for the liquid state, J. Solution Chem., 9(12), 895-909.

Bourles, B., P. Brandt, G. Caniaux, M. Dengler, Y. Gouriou, E. Key, R. Lumpkin, F. Marin, R. L. Molinari, and C. Schmid (2007), African Monsoon Multidisciplinary Analysis (AMMA): Special measurements in the tropical Atlantic, CLIVAR Exchanges, 12(2), 7-9.

Bourles, B., et al. (2008), The PIRATA program: History, accomplishments and future directions. Bull. Am. Meteorol. Soc., 89(8), 1111-1125, doi:10.1175/2008BAMS2462.1

Broecker, W. S., T. -H. Peng, and M. Stuiver (1978), An estimate of the upwelling rate in the equatorial Atlantic based on the distribution of bomb radiocarbon, J. Geophys. Res., 83(C12), 6179-6186.

Cromwell, T. (1953), Circulation in a meridional plane in the central equatorial Pacific. J. Mar. Res., 12, 196-213.

Foltz, G. R., S. A. Grodsky, J. A. Carton, and M. J. McPhaden (2003), Seasonal mixed layer heat budget of the tropical Atlantic Ocean, J. Geophys. Res., 108(C5), 3146, doi:10.1029/2002JC001584.

Gouriou, Y., and G. Reverdin (1992), Isopycnal and diapycnal circulation of the upper equatorial Atlantic Ocean in 1983-1984, J. Geophys. Res., 97(C3), 3543-3572, doi:10.1029/91JC02935.

Grodsky, S. A., and J. A. Carton (2002), Surface drifter pathways originating in the equatorial Atlantic cold tongue, Geophys. Res. Lett., 29(23), 2147, doi:10.1029/2002GL015788.

Grodsky, S. A., J. A. Carton, and C. R. McClain (2008), Variability of upwelling and chlorophyll in the equatorial Atlantic, Geophys. Res. Lett., 35, L03610, doi:10.1029/2007GL032466.

Hayes, S. P., P. Chang, and M. J. McPhaden (1991), Variability of the sea surface temperature in the eastern equatorial Pacific during 1986-1988, J. Geophys. Res., 96, 10,553-10,566, doi:10.1029/91JC00942.

Helber, R. W., and R. H. Weisberg (2001), Equatorial upwelling in the western Pacific warm pool, J. Geophys. Res., 106(C5), 8989-9003, doi:10.1029/2000JC000401

Hormann, V., and P. Brandt (2009), Upper equatorial Atlantic variability during 2002 and 2005 associated with equatorial Kelvin waves, J. Geophys. Res., 114, C03007, doi:10.1029/2008JC005101.

Jayne, S. R., and J. Marotzke (2001), The dynamics of ocean heat transport, Rev. Geophys., 39(3), 385-411, doi:10.1029/2000RG000084.

Johnston, T. M. S., and D. L. Rudnick (2009), Observations of the transition layer, J. Phys. Oceanogr., 39, 780-797.

Klein, B., and M. Rhein (2004), Equatorial upwelling rates inferred from helium isotope data: A novel approach, Geophys. Res. Lett., 31, L23308, doi:10.1029/2004GL021262.

Knauss, J. A. (1963), Equatorial current systems, in The Sea, vol. 2, pp. 235-252, Wiley-Interscience.

Kolodziejczyk, N., B. Bourles, F. Marin, J. Grelet, and R. Chuchla (2009), The seasonal variability of the equatorial undercurrent and the South Atlantic Undercurrent at $10^{\circ} \mathrm{W}$ as inferred from recent in-situ data, J. Geophys. Res., 114, C06014, doi:10.1029/2008JC004976.

Longhurst, A. (1993), Seasonal cooling and blooming in the tropical oceans, Deep Sea Res., Part I, 40, 2145-2165.

Lupton, J. E. (1998), Hydrothermal helium plumes in the Pacific Ocean, J. Geophys. Res., 103(C8), 15,853-15,868.

Marin, F., G. Caniaux, B. Bourles, H. Giordani, Y. Gouriou, and E. Key (2009), Why were sea surface temperatures so different in the eastern equatorial Atlantic in June 2005 and 2006?, J. Phys. Oceanogr., 39, $1416-1431$.

Meinen, C. S., M. J. McPhaden, and G. C. Johnson (2001), Vertical velocities and transports in the equatorial Pacific during 1993-1999, J. Phys. Oceanogr., 31, 3230-3248

Molinari, R., S. Bauer, D. Snowden, G. C. Johnson, B. Bourles, Y. Gouriou, H. Mercier, and F. Schott (2003), A comparison of kinematic evidence for tropical cells in the Atlantic and Pacific Oceans, in Interhemispheric Water Exchange in the Atlantic Ocean, edited by P. Malanotte-Rizzoli and G. Goni, Elsevier Oceanogr. Ser., 68, Elsevier, New York.

Naegler, T., P. Ciais, K. B. Rodgers, and I. Levin (2006), Excess radiocarbon constraints on air-sea gas exchange and the uptake of $\mathrm{CO}_{2}$ by the oceans, Geophys. Res. Lett., 33, L11802, doi:10.1029/2005GL025408.

Osborn, T. R. (1980), Estimates of the local rate of vertical diffusion from dissipation measurements, J. Phys. Oceanogr., 10, 83-89. 
Peter, A.-C., M. Le Hénaff, Y. du Penhoat, C. Menkes, F. Marin, J. Vialard, G. Caniaux, and A. Lazar (2006), A model study of the seasonal mixed layer heat budget in the equatorial Atlantic, J. Geophys. Res., 111, C06014, doi:10.1029/2005JC003157.

Peters, H., M. Gregg, and T. Sanford (1994), The diurnal cycle of the upper equatorial ocean: Turbulence, fine-scale shear, and mean shear, J. Geophys. Res., 99(C4), 7707-7723, doi:10.1029/93JC03506.

Prandke, H., and A. Stips (1998), Test measurements with an operational microstructure turbulence profiler: Detection limit of dissipation rates, Aquat. Sci., 60, 191-209.

Reynolds, R. W., T. M. Smith, C. Liu, D. B. Chelton, K. S. Casey, and M. G. Schlax (2007), Daily high-resolution blended analyses for sea surface temperature, J. Clim., 20, 5473-5496.

Schott, F., M. Dengler, and R. Schoenefeldt (2002), The shallow overturning circulation of the Indian Ocean, Prog. Oceanogr., 53, 57-103.

Sültenfuß, J., M. Rhein, and W. Roether (2009), The Bremen mass spectrometric facility for the measurement of helium isotopes, neon, and tritium in water, Isot. Environ. Health Stud., 45(2), 1-13.

Sweeney, C., E. Gloor, A. R. Jacobson, R. M. Key, G. McKinley, J. L. Sarmiento, and R. Wanninkhof (2007), Constraining global air-sea gas exchange for $\mathrm{CO}_{2}$ with recent bomb ${ }^{14} \mathrm{C}$ measurements, Global Biogeochem. Cycles, 21, GB2015, doi:10.1029/2006GB002784.

Wanninkhof, R. (1992), Relationship between wind speed and gas exchange over the Ocean, J. Geophys. Res., 97(C5), 7373-7382, doi:10.1029/ 92JC00188.
Weingartner, T. J., and R. H. Weisberg (1991a), On the annual cycle of equatorial upwelling in the central Atlantic ocean, J. Phys. Oceanogr., $21,68-82$.

Weingartner, T. J., and R. H. Weisberg (1991b), A description of the annual cycle in sea surface temperature and upper ocean heat in the equatorial Atlantic, J. Phys. Oceanogr., 21, 83-96.

Weisberg, R. H., and L. Qiao (2000), Equatorial upwelling in the central Pacific estimated from moored velocity profilers, J. Phys. Oceanogr., 30, 105-124.

Weiss, R. F. (1970), Helium isotope effect in solution in water and seawater, Science, 168, 247-248.

Willett, C. S., R. R. Leben, M. M. Lavin (2006), Eddies and tropical instability waves in the eastern tropical Pacific: A review, Prog. Oceanogr., $69,218-238$

Wyrtki, K. (1981), An estimate of equatorial upwelling in the Pacific, J. Phys. Oceanogr., 11, 1205-1210.

B. Bourles, IRD, LEGOS, CRHOB, Résidence les Cocotiers, 08 B.P 841, Cotonou, Benin.

M. Dengler and R. Hummels, IFM-GEOMAR, FB1/PO, Duesternbrooker Weg 20, D-24105 Kiel, Germany.

S. Hüttl-Kabus and J. Sültenfuß, Bundesamt für Seeschifffahrt und Hydrographie, Bernhard-Nocht-Strasse 78, D-20359 Hamburg, Germany. M. Rhein, Institut für Umweltphysik, Universität Bremen, Otto-HahnAllee, Geb. NW1, D-28359 Bremen, Germany. (mrhein@physik.unibremen.de) 